\title{
miR-27a-mediated antiproliferative effects of metformin on the breast cancer cell line MCF-7
}

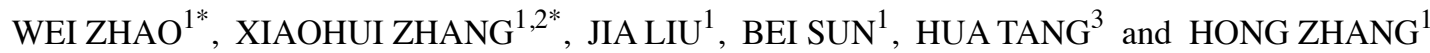 \\ ${ }^{1}$ Key Laboratory of Hormones and Development (Chinese Ministry of Health), Metabolic Disease Hospital, \\ Endocrinology Institute, Tianjin Medical University, Tianjin 300070; ${ }^{2}$ Department of Nutrition, First Teaching Hospital \\ of Tianjin University of Traditional Chinese Medicine, Tianjin 300381; ${ }^{3}$ Tianjin Life Science Research Center and \\ Department of Microbiology, School of Basic Medical Sciences, Tianjin Medical University, Tianjin 300070, P.R. China
}

Received April 27, 2016; Accepted June 21, 2016

DOI: $10.3892 /$ or.2016.5199

\begin{abstract}
Metformin was demonstrated to have effects on breast cancer, and microRNA-27a (miR-27a) is a prognostic marker for breast cancer progression and patient survival. AMPK $\alpha 2$ was found to be a suppressor in breast cancer MCF-7 cells. Therefore, the present study aimed to explain this phenomenon in regards to the relationship between microRNAs (miRNAs) and their target genes and to predict how AMPK $\alpha 2$ may be a downstream target gene of miR-27a, thus exploring the new mechanism of metformin in the treatment of breast cancer regarding miRNAs. The MTT assay was used to assess whether metformin can inhibit the growth of breast cancer MCF-7 cells. The levels of miR-27a and AMPK $\alpha 2$ mRNA were examined using RT-PCR, and the expression levels of AMPK $\alpha 2$ and caspase-3 were determined by western blot analyses after MCF-7 cells were treated with metformin. The association of miR-27a and AMPK $\alpha 2$ was confirmed by transfecting cells with miR-27a mimics, miR-27a inhibitors and its negative control (NC), respectively. A luciferase assay was conducted to detect the miR-27a binding to the AMPK $\alpha 2$ 3'-untranslated region (3'-UTR). The results of the MTT assay showed that metformin suppressed the growth of MCF-7 cells in a dose- and time-dependent manner. miR-27a was downregulated, and AMPKa2 was upregulated after intervention with metformin, and caspase- 3 was activated. Transfection tests showed that the expression of AMPK $\alpha 2$ was downregulated in the MCF-7 cells after transfection of the miR-27a mimics. The luciferase assay verified the binding
\end{abstract}

Correspondence to: Dr Hong Zhang, Key Laboratory of Hormones and Development (Chinese Ministry of Health), Metabolic Disease Hospital, Endocrinology Institute, Tianjin Medical University, Tianjin 300070, P.R. China

E-mail: zh80008@163.com

${ }^{*}$ Contributed equally

Key words: metformin, MCF-7, cell apoptosis, microRNA-27a, AMPK $\alpha 2$ of miR-27a to the AMPK $\alpha 2$ 3'-UTR. In conclusion, metformin inhibited MCF-7 cell growth, and miR-27a plays a vital role in this process by targeting AMPK $\alpha 2$.

\section{Introduction}

Breast cancer has become one of the most common malignant tumors, and its incidence rate has rapidly grown in recent years. There is evidence that diabetes can increase the risk of breast cancer and is related with its prognosis. Clinically, these two diseases emerge simultaneously (1). Metformin is a biguanide drug that is widely used in patients with type 2 diabetes (2). Recently, a large number of epidemiological data showed that metformin can reduce the incidence of breast cancer and improve the prognosis (3).

MicroRNAs (miRNAs) are small, non-coding RNAs (4-6). Mature miRNAs are single-stranded, containing 19-25 nt. miRNAs post-transcriptionally repress gene expression by recognizing complementary target sites in the 3'-untranslated region (3'-UTR) of target mRNAs. Increasing evidence supports an important role for miRNAs in the processes of proliferation, apoptosis, invasion/metastasis and angiogenesis $(7,8)$.

MicroRNA-27a (miR-27a) is located on chromosome 19 and is highly expressed in breast, gastric, pancreatic and colon cancer as an oncogenic miRNA (9-11). miR-27a regulates cell growth and differentiation and can mediate drug resistance in a dose-dependent manner $(9,12)$. Furthermore, miR-27a promotes tumor cell metastasis by inducing epithelialmesenchymal transition. In breast cancer cells, miR-27a participates in cell apoptosis, cell cycle checkpoints and metabolism $(10,13,14)$.

AMP-activated protein kinase (AMPK), which functions as a cellular energy sensor, occurs as a heterotrimer composed of $\alpha 1, \alpha 2, \beta 1, \beta 2, \gamma 1$ and $\gamma 2$ subunits. The $\alpha$-subunit serves as the catalytic subunit, whereas the $\beta$ - and $\gamma$-subunits serve regulatory functions $(15,16)$. AMPK $\alpha 1$ is widely expressed in cells, and the AMPK 22 subunit is only expressed in hepatocytes, skeletal muscle and cardiac muscle cells. Current studies on metabolism have focused on the role of AMPK $\alpha 2$. Jørgensen et al found that the uptake of glucose in skeletal muscle cells was increased after activation of AMPK by 
AICAR, and the AMPK $\alpha 2$ subunit plays an important role in this process, while the AMPK $\alpha 1$ subunit was not activated (17). Musi et al found that metformin activated AMPK in the liver cells of mice, which caused a decrease in hepatic glucose output and further confirmed that this involved AMPK $\alpha 2$ $172^{\text {thr }}$ phosphorus acid increase (18). However, there are few studies on cancer regarding AMPK $\alpha 2$.

Recently, Fox et al found that AMPK 22 was widely suppressed in breast cancer tissues and MCF-7 cells (19). Kim et al demonstrated that AMPK $\alpha 2$ was uniquely suppressed in tumors compared with normal samples (20). However, the mechanism explaining how AMPK $\alpha 2$ mRNA expression is downregulated remains unknown.

Therefore, the present study aimed to explain this phenomenon from the relationship between miRNAs and their target genes and to predict how AMPK $\alpha 2$ is a downstream target gene of miR-27a, thus, exploring a new mechanism for metformin in the treatment of breast cancer regarding miRNAs.

\section{Materials and methods}

Cell lines and cell culture. The MCF-7 cell line was obtained from the Tumor Cell Bank at the Chinese Academy of Medical Sciences. Cells were cultured in RPMI-1640 supplemented with $10 \%$ fetal bovine serum (FBS), $100 \mathrm{U} / \mathrm{ml}$ penicillin and $100 \mu \mathrm{g} / \mathrm{ml}$ streptomycin in humidified air at $37^{\circ} \mathrm{C}$ with $5 \%$ $\mathrm{CO}_{2}$. The media were replaced every 1-2 days.

MTT assay. MCF-7 cells were seeded in 96-well plates at 4,000 cells/well in $200 \mu \mathrm{l}$ cell culture medium and incubated at $37^{\circ} \mathrm{C}$ for $24 \mathrm{~h}$. All cells were divided into 3 groups: i) blank wells containing medium only; ii) untreated control cells; and iii) test cells treated with different concentrations of metformin. After incubation for $48 \mathrm{~h}$, the cells were incubated with $20 \mu \mathrm{l} \mathrm{MTT} \mathrm{(final} \mathrm{concentration} \mathrm{of} 0.5 \mathrm{mg} / \mathrm{ml}$ ) at $37^{\circ} \mathrm{C}$ for $4 \mathrm{~h}$. The medium was removed, and the precipitated formazan was dissolved in $150 \mu \mathrm{l}$ dimethyl sulfoxide (DMSO). After shaking for $15 \mathrm{~min}$, the absorbance at $490 \mathrm{~nm}$ was detected. This procedure was repeated at 24,48 and $72 \mathrm{~h}$ after transfection. MTT was carried out 3 times.

Cell transfection. In brief, specific concentrations of mimics or inhibitors of miR-27a (GenePharma, Shanghai, China) were transfected into cell cultures using the transfection reagent Lipofectamine 2000 (Invitrogen, Carlsbad, CA, USA) to activate or inactivate miR-27a activity, respectively. Negative controls were used for both reactions (see the RNA oligo sequences in Table I). Six hours after transfection, the transfection solution was replaced with complete culture medium. For RNA extraction and protein isolation, cells were treated for $48 \mathrm{~h}$, and were then harvested. miRNA transfection efficiencies were determined by real-time PCR.

MTT assay after transfection. Cells were plated in 96-well plates at $10^{4}$ /well and transfected with miR-27a mimics, miR-27a inhibitors and their corresponding negative control. After transfection, the cells were cultured for $48 \mathrm{~h}$. The effects of miR-27a mimics and miR-27a inhibitors on cell growth and viability were determined by the MTT assay as described above.
Table I. RNA oligo sequences.

Name RNA oligo sequence (5'-3')

hsa-miR-27a mimics

MicroRNA mimic NC

UUCACAGUGGCUAAGUUCCGC

hsa-miR-27a inhibitors UUGUACUACACAAAAGUACUG

MicroRNA inhibitor NC GCGGAACUUAGCCACUGUGAA CAGUACUUUUGUGUAGUACAA

$\mathrm{NC}$, negative control.

Table II. Reverse transcription and PCR primers.

\begin{tabular}{lll}
\hline Gene name & & \multicolumn{2}{c}{ RNA oligo sequence (5'-3') } \\
\hline U6 & F & GCTTCGGCAGCACATATACTAAAAT \\
miR-27a & F & TTCACAGTGGCTAAGTTCCGC \\
AMPKa2 & F & GCCAAGAAGCAAATGAGAATG \\
& R & GACACAACGCAAACTCCTGA \\
GAPDH & F & ACCACAGTCCATGCCATCAC \\
& R & TCCACCACCCTGTTGCTGTA
\end{tabular}

F, forward; R, reverse.

Quantitative $R T-P C R$. In the present study, we validated the expression levels of miR-27a using tail real-time PCR. The reverse transcription and PCR primers used are listed in Table II. Briefly, RNA was extracted using an miRNA isolation kit (Invitrogen). Then, $1 \mu \mathrm{g}$ RNA was reverse transcribed into cDNA using the RT primer. Subsequently, miRNAs were PCR amplified on a real-time PCR system using specific forward primers and a universal reverse primer. The qRT-PCR consisted of 40 cycles $\left(95^{\circ} \mathrm{C}\right.$ for $5 \mathrm{sec}$ and $60^{\circ} \mathrm{C}$ for $\left.20 \mathrm{sec}\right)$ after an initial denaturation step $\left(95^{\circ} \mathrm{C}\right.$ for $\left.10 \mathrm{sec}\right)$. The expression levels were normalized against human small nuclear U6 RNA and measured by the comparative $\mathrm{Ct}\left({ }^{\Delta \Delta} \mathrm{Ct}\right)$ method. Relative fold-changes were calculated by the equation $2^{-\Delta \Delta \mathrm{Ct}}$.

For mRNA expression analysis, total cellular RNA was isolated and reverse transcribed to cDNA. Real-time PCR amplification was performed using SYBR ${ }^{\circledR}$ Premix Ex Taq ${ }^{\mathrm{TM}}$ (RR041A; Takara). The PCR reaction contained $1 \mu \mathrm{l}$ RT product, $10 \mu 12 \mathrm{X}$ SYBR Premix Ex Taq, $1 \mu 1$ forward primer and $1 \mu \mathrm{l}$ reverse primer (5 $\mu \mathrm{mol} / 1 \mathrm{each})$, and nuclease-free water in a final volume of $20 \mu \mathrm{l}$. Standard PCR samples were analyzed using a Bio-Rad iQ5 thermal cycler. Melting curves were generated for each real-time RT-PCR to verify the specific amplification products and primer dimers of each PCR reaction. All quantitative PCR reactions were performed in triplicate. The primers are listed in Table II. The expression levels of the target genes were normalized to GAPDH. The qRT-PCR was carried out at least 3 times.

Western blot analysis. Cells were lysed with RIPA buffer. The cytosolic extracts were prepared by centrifuging the lysates twice at $12,000 \mathrm{rpm}$ for $10 \mathrm{~min}$ at $4^{\circ} \mathrm{C}$. The protein concentration in each lysate was measured by the bicinchoninic acid assay (BCA). Equal amounts of protein were separated 

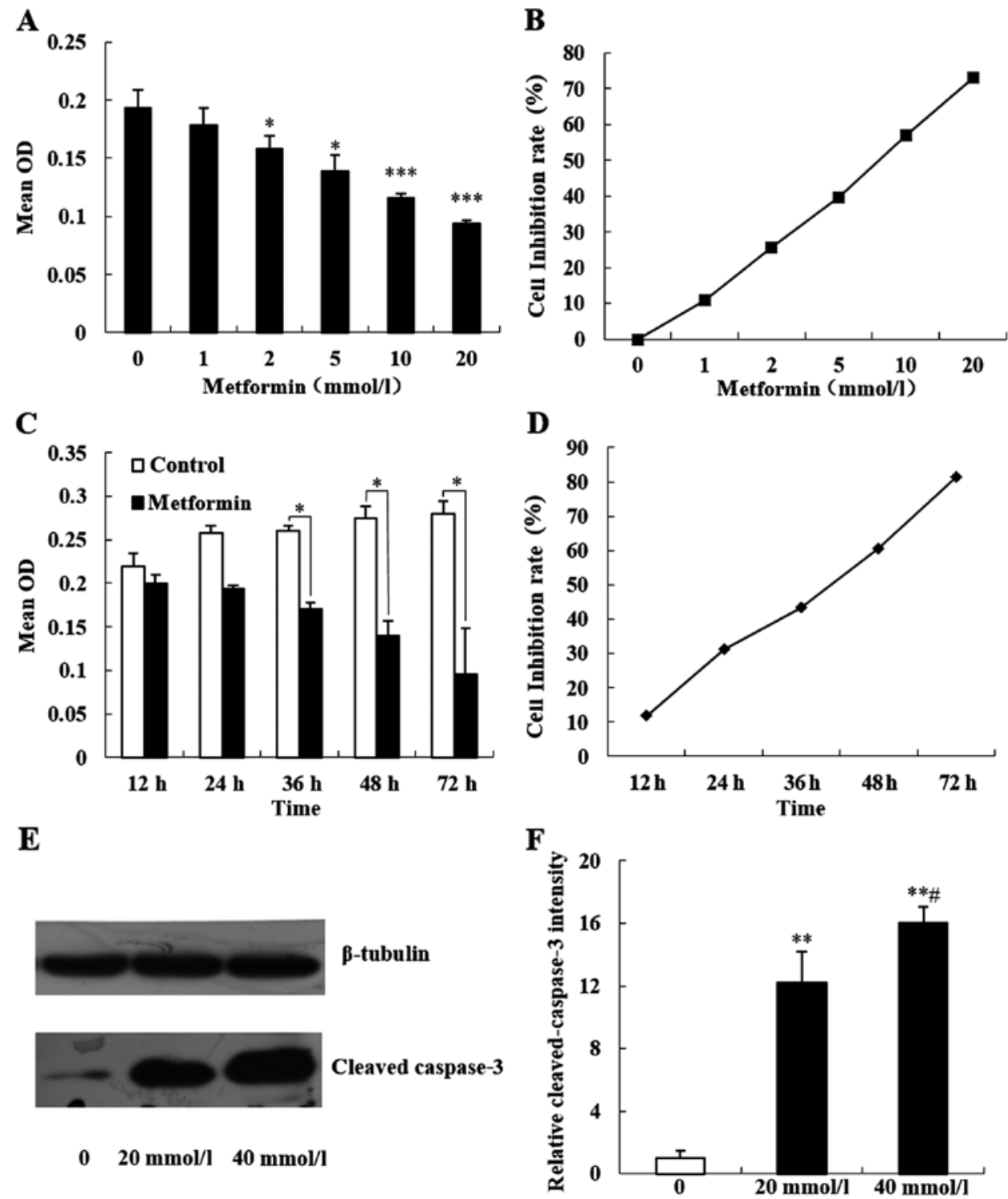

Figure 1. Metformin-induced apoptosis in MCF-7 cells. (A) All OD data showed that increasing metformin concentrations decreased the mean OD values ( $\mathrm{P}<0.05$ and ${ }^{* * *} \mathrm{P}<0.001$ compared to the control group). (B) A total of $20 \mathrm{mmol} / 1$ metformin inhibited the cell growth at the rate of $\sim 80 \%$. (C) Cell growth was obviously inhibited in the MCF-7 cells following treatment with a $20 \mathrm{mmol} / 1$ concentration of metformin with prolongation of time ("P<0.05). (D) Cell growth was significantly different following treatment with metformin for 36,48 and $72 \mathrm{~h}$ when compared with the $12 \mathrm{~h}$ group as detected by ANOVA. (E and F) In the MCF-7 cells, $20 \mathrm{mmol} / 1$ metformin activated the cleavage of caspase- 3 and $40 \mathrm{mmol} / 1$ metformin augmented this tendency $\left({ }^{* *} \mathrm{P}<0.01\right.$; ${ }^{*} \mathrm{P}<0.05$ compared to $20 \mathrm{mmol} / \mathrm{l})$.

by SDS-PAGE. After electrophoresis, proteins were transferred onto a nitrocellulose membrane and blocked in 5\% BSA in Tris-buffered saline and Tween-20 (TBST) at room temperature for $2 \mathrm{~h}$, then, the membrane was incubated with a rabbit anti-AMPK $\alpha 2$ monoclonal antibody (1:1,000; \#2757; CST) or the polyvinylidene fluoride (PVDF) membrane was incubated with a rabbit anti-caspase-3 polyclonal antibody (1:1,000; \#25546-1-AP; Proteintech) overnight at $4^{\circ} \mathrm{C}$. After thorough rinsing with TBST, the membranes were incubated with peroxidase-conjugated secondary antibody (1:10,000; \#E030120; HRP; Sanjiang) for $1 \mathrm{~h}$. After rinsing, chemiluminescent detection was performed using an enhanced chemiluminescence (ECL) western blot detection kit followed by exposure and development of the X-ray film. Western blot results were analyzed by densitometry. The western blotting was carried out at least 3 times.
Luciferase reporter assay for targeting the AMPK 22 3'-UTR. For the luciferase reporter experiments, a human AMPK $\alpha 2$ 3'-UTR segment of 207 base pairs was amplified from rat cDNA by PCR and inserted into the pMIR-REPORT luciferase vector with a cytomegalovirus promoter using the $S a c I$ and HindIII sites immediately downstream from the stop codon of luciferase. The following sets of primers were used to generate specific fragments: for rat AMPK $\alpha 23^{\prime}$-UTR, forward primer 5'-GGACTAGTAAATGTTGGCTGAAGCTG-3' and reverse primer 5'-CCCAAGCTTTGTTGCATTCAAAATCCACT-3'. Nucleotide substitutions were introduced by PCR mutagenesis to yield mutated binding sites. The pMIR-AMPK $\alpha 2$ 3'-UTR, miR-27a mimics, and pMIR-REPORT $\beta$-galactosidase control plasmid were then co-transfected into MCF-7 cells for $24 \mathrm{~h}$. The luciferase activity was measured following the manufacturer's instructions. Experiments were performed in triplicate. 

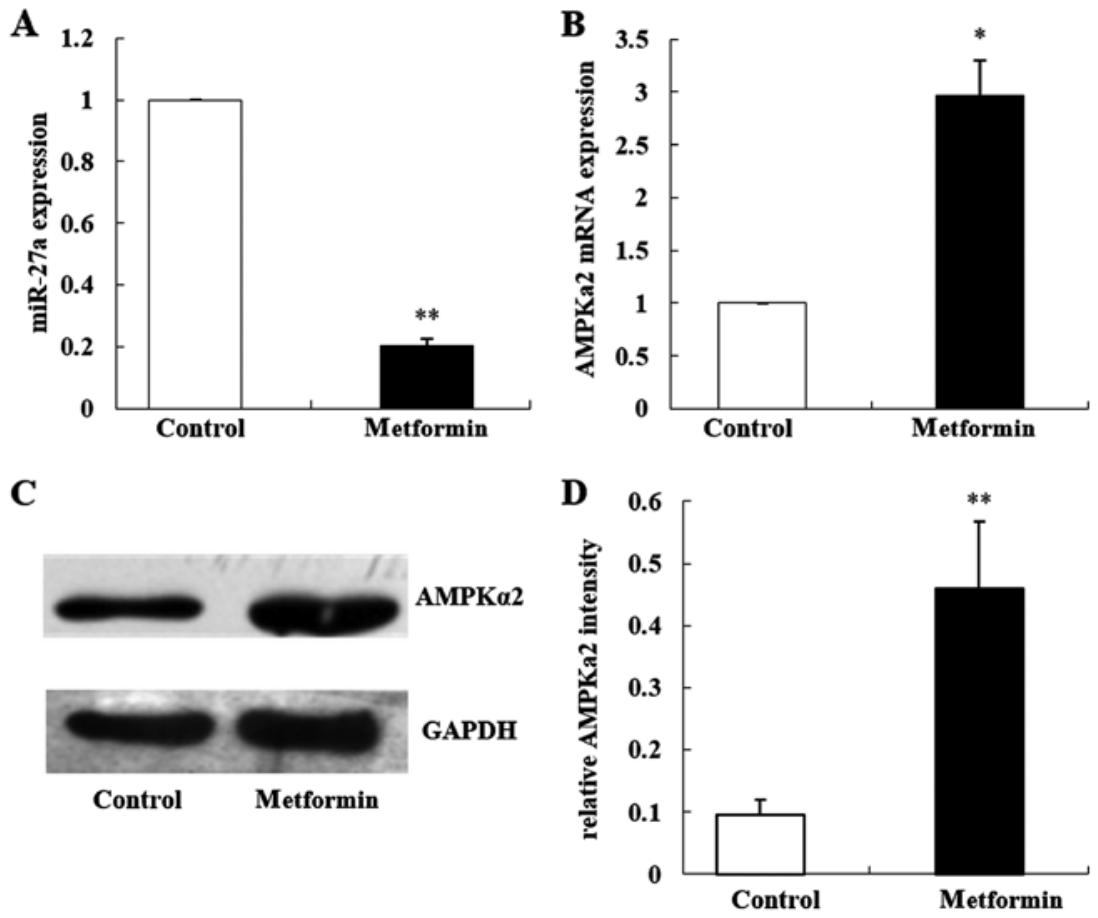

Figure 2. Changes in miR-27a and AMPK $\alpha 2 \mathrm{mRNA}$ and protein levels following treatment with metformin. (A) After intervention of metformin at a $20 \mathrm{mmol} / 1$ concentration for $48 \mathrm{~h}$, qRT-PCR results showed that miR-27a expression was significantly decreased compared with the control group $\left({ }^{* *} \mathrm{P}<0.01\right)$. (B) After intervention of metformin at a $20 \mathrm{mmol} / 1$ concentration for $48 \mathrm{~h}$, qRT-PCR results showed that AMPK $\alpha 2 \mathrm{mRNA}$ expression was significantly increased compared with the control group ( $\mathrm{P}<0.05)$. ( $\mathrm{C}$ and $\mathrm{D})$ Western blot results showed increased AMPK $\alpha 2$ expression at the protein level ("* $\mathrm{P}<0.01)$.

Statistical analysis. Each experiment had three or more replicates. All data were expressed as the mean \pm standard deviation (SD). Statistical analyses were performed with a Student's t-test or analysis of variance (ANOVA), and a $\mathrm{P}<0.05$ was considered to indicate a statistically significant result $\left({ }^{*} \mathrm{P}<0.05,{ }^{* *} \mathrm{P}<0.01\right.$ and ${ }^{* * *} \mathrm{P}<0.001$ are indicated in the figures).

\section{Results}

Metformin inhibits the growth of MCF-7 cells and promotes apoptosis. In order to investigate the effects of metformin on the proliferation and apoptosis of the human breast cancer cell line MCF-7, MCF-7 cells were cultured in vitro with final concentrations of $1,2,5,10$ and $20 \mathrm{mmol} / 1$ of metformin and incubated for $48 \mathrm{~h}$. The MTT method was used to detect cell optical density (OD) for increasing concentrations of metformin. The average OD value was gradually decreased, while the cell proliferation inhibition rate was significantly increased (Fig. 1A and B; P<0.05). Then, a final concentration of $20 \mathrm{mmol} / \mathrm{l}$ metformin was used to act on MCF-7 cells for $12,24,36,48$ and $72 \mathrm{~h}$, respectively. MTT results showed that increasing metformin intervention times had an average OD value that was gradually decreased, and the cell proliferation inhibition rate was significantly increased (Fig. 1C and D; $\mathrm{P}<0.05$ ).

Caspase-3 is a key member of the caspase family of apoptosis execution and is activated in the early stage of apoptosis. Activated caspase- 3 is decomposed into two large subunits $(17 \mathrm{kDa})$ and two small subunits (13 kDa). We treated MCF-7 cells with 20 and $40 \mathrm{mmol} / 1$ metformin to react for $48 \mathrm{~h}$. Western blot results showed that the expression of $17 \mathrm{kDa}$ caspase-3 in the human breast cancer MCF-7 cells was significantly increased (Fig. 1E and F; P<0.05).

Metformin decreases the expression of miR-27a and upregulates AMPKa2 expression in MCF-7 cells. Our previous study found that the primary culture from liver tissues of C57BL/6 mice had the AMPK-specific activator AICAR, and the expression of the miR-27 family was significantly inhibited (21). Metformin was found to play a major role in breast cancer through the AMPK signaling pathway. In the present study, we treated MCF-7 cells with $20 \mathrm{mmol} / \mathrm{l}$ metformin for 48 h. qRT-PCR results showed that after metformin intervention, the expression of miR-27a was significantly decreased by $\sim 80 \%$ when compared with the control group (Fig. 2A; $\mathrm{t}=-5.37, \mathrm{P}=0.006$ ).

Fox et al found that the expression of AMPK $\alpha 2$ in breast cancer tissues and MCF-7 cells was inhibited, and AMPK $\alpha 2$ is a tumor-suppressor (19). In order to investigate the effects of metformin on the expression of AMPK $\alpha 2$, we observed the effects of metformin on the expression of AMPK $\alpha 2$ together with miR-27a using qRT-PCR and western blot analyses. The results showed that the expression of AMPK $\alpha 2$ mRNA was 3.3-fold higher when compared with that noted in the control group (Fig. 2B; $\mathrm{P}<0.05$ ), and the expression of the AMPK $\alpha 2$ protein was 4-fold higher when compared with that noted in the control group (Fig. 2C and D; $\mathrm{P}<0.01$ ).

miR-27a inhibits apoptosis in MCF-7 cells and promotes proliferation. In order to investigate the role of miR-27a in inhibiting proliferation and promoting apoptosis in MCF-7 cells, miR-27a mimics and miR-27a inhibitors were 

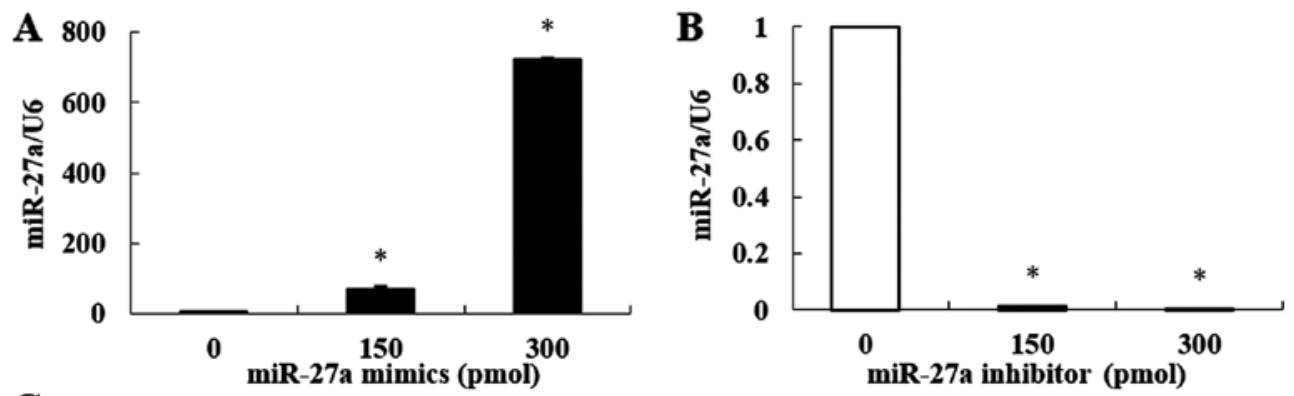

C

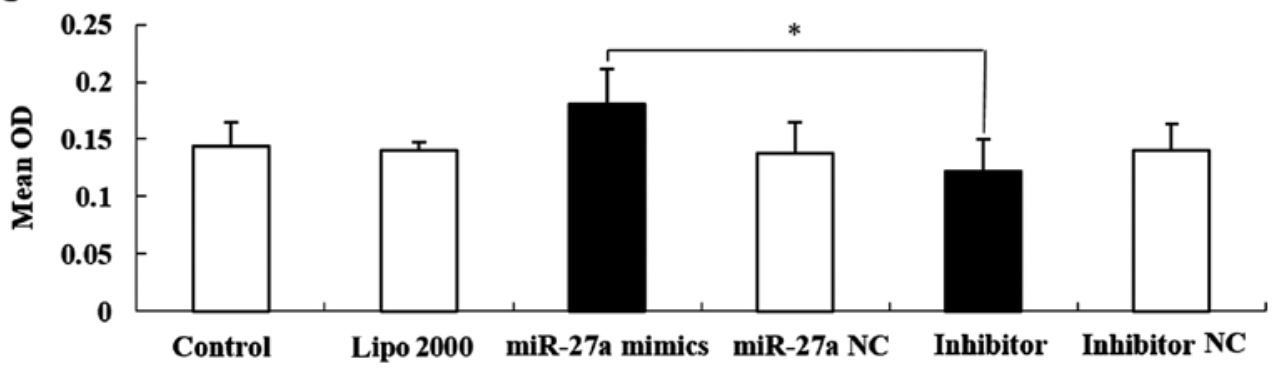

D

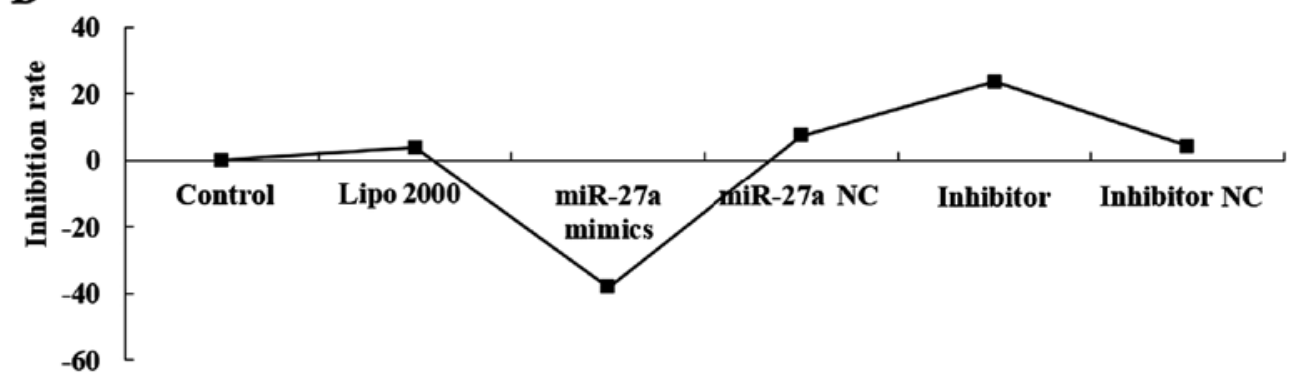

$\mathbf{E}$
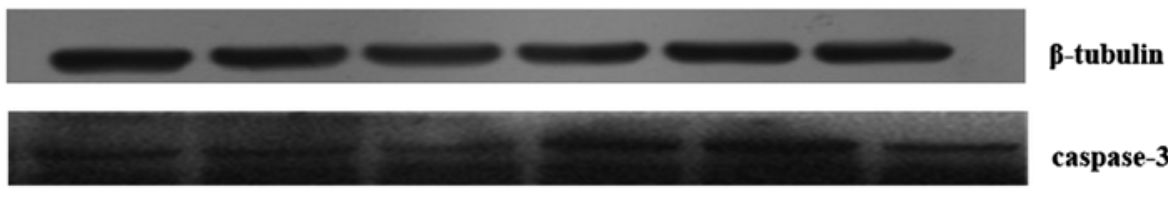

caspase-3

$\mathbf{F}$
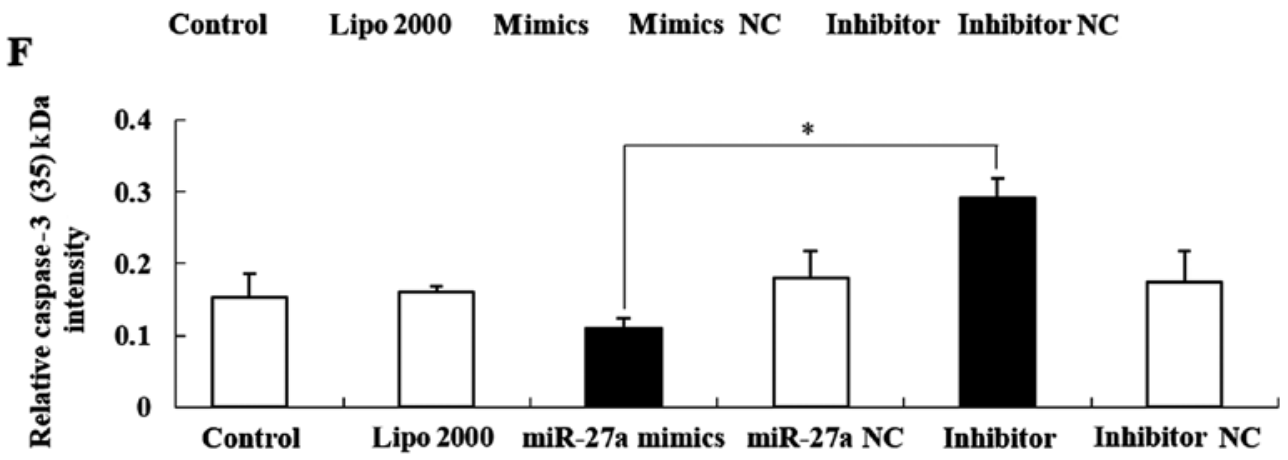

Figure 3. miR-27a suppresses cell viability (A) The efficacy of transfection of the miR-27a mimics and miR-27a inhibitors. In the group transfected with the miR-27a mimics, the miR-27a expression was significantly increased $\left({ }^{*} \mathrm{P}<0.05\right)$. (B) In the group transfected with the inhibitor, the expression of miR-27a was significantly inhibited ( $\mathrm{P}<0.05)$. (C and D) MTT results showed that in the miR-27a mimic group, the mean OD value was significantly higher than that in the other groups, and the proliferation inhibition rate was decreased. In the inhibitor group, the mean OD value was the lowest, and it had the highest proliferation inhibition rate, and the variance between these two groups had no significant difference $(* \mathrm{P}<0.05)$. (E and F) Overexpression of miR-27a caused a decreaase in caspase-3 protein levels, while the expression levels were increased in the groups transfected with the miR-27a inhibitor, and the variance between these two groups was significantly different $\left({ }^{*} \mathrm{P}<0.05\right)$.

transfected into MCF-7 cells. qRT-PCR assays showed that the expression of miR-27a was increased nearly 1,000-fold when $300 \mathrm{pmol}$ miR-27a mimics were transfected into the cells, and the expression of miR-27a was almost completely inhibited by 300 pmol of the miR-27a inhibitor (Fig. 3A and B; P<0.05).
Furthermore, we used 300 pmol miR-27a mimics and miR-27a inhibitors to transfect MCF-7 cells, and the OD values were determined by the MTT method. The groups with overexpressed miR-27a had the highest OD values and the groups transfected with the inhibitors had the lowest 
$\mathbf{A}$

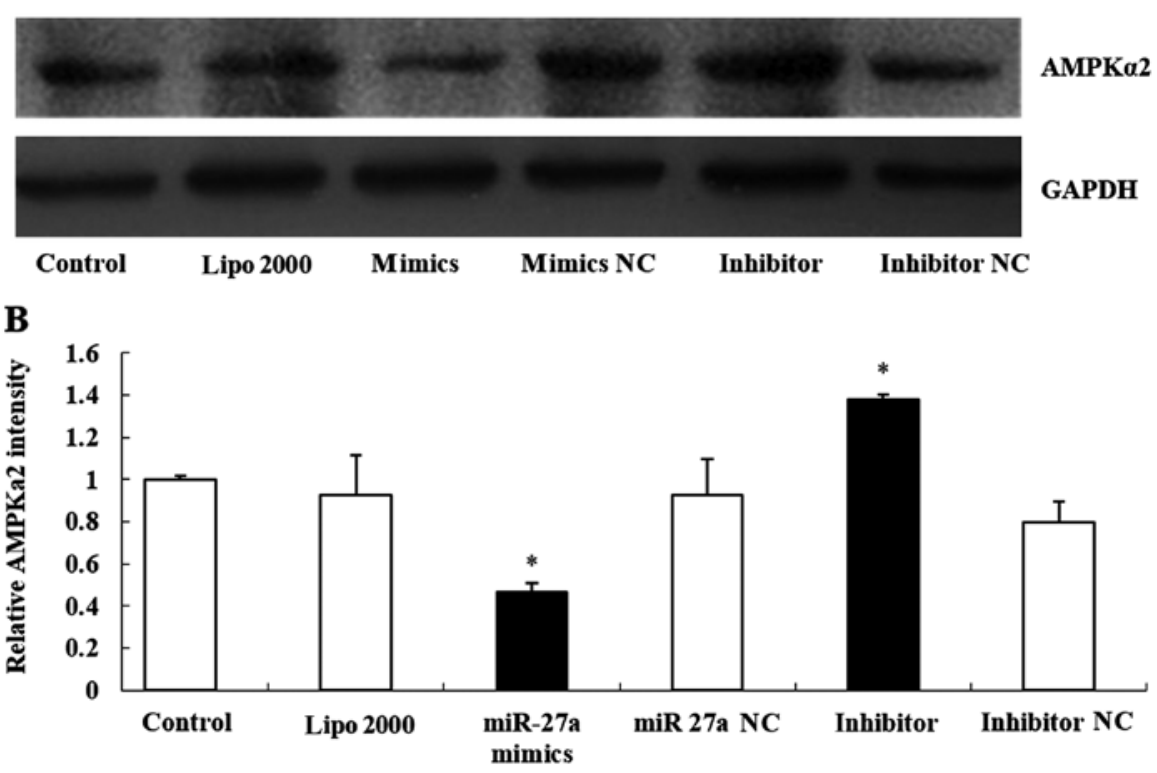

C

miR-27a

Human AMPK a2 $^{3}$ '-UTR

Mutated AMPK ${ }_{02}$ 3'-UTR binding site

D

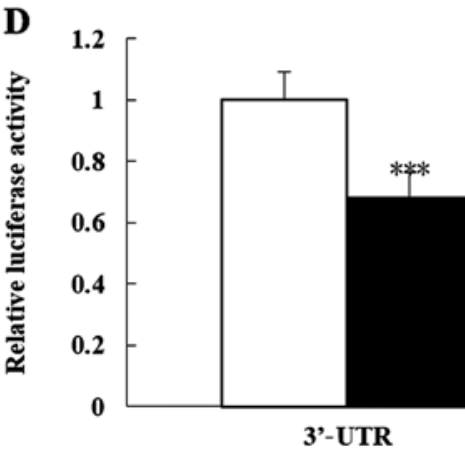

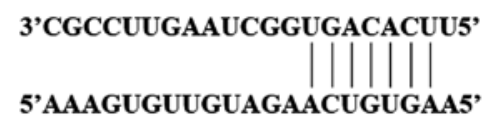

Seed sequence 3' actgtgaa 5 '

Figure 4. miR-27a binds to the 3'-UTR of AMPK $\alpha 2$ to suppress its expression. (A and B) The level of AMPK $\alpha 2$ mRNA was significantly decreased; and in the inhibitor group, AMPK $\alpha 2$ mRNA expression showed a concentration-dependent increase, while in the control groups, there were no changes in AMPK $\alpha 2$ mRNA and protein levels ( $($ P $<0.05$ ). (C) Alignment of AMPK $\alpha 2$ 3'-UTR (and mutated AMPK $\alpha 2$ 3'-UTR) sequence with mature miR-27a based on bioinformatic predictions (www. targetscan.org, www. microrna. org; and www. ebi. ac. ukl). The 5'-end of the mature miR-27a was the seed sequence and had perfect complementarity with 7 nucleotides in the 3'-UTR of AMPK $\alpha 2$. In the mutated sequence (small caps identifying mutated nucleotides), such complementarity was lost. (D) MCF-7 cells were transfected with luciferase reporter vectors containing either the wild-type (NC) or mutant (MUT) AMPK $\alpha 2$ 3'-UTR, together with the miR-27a mimic $(50 \mathrm{nM})$. The Renilla luciferase vector was co-transfected in each incubation and normalized $\left({ }^{* * *} \mathrm{P}<0.001\right)$.

OD values. Therefore, we concluded that overexpression of miR-27a promotes human breast cancer cell MCF-7 proliferation and silencing miR-27a expression inhibits MCF-7 cell proliferation (Fig. 3C and D; $\mathrm{P}<0.05$ ). In addition, we used western blot analyses to detect the expression of caspase-3 $(17 \mathrm{kDa})$ in each group. The results showed that the expression of caspase-3 (17 kDa) in the miR-27a overexpression group was significantly decreased, and in the inhibitor group was significantly increased (Fig. $3 \mathrm{E}$ and $\mathrm{F} ; \mathrm{P}<0.05$ ).

miR-27a targets AMPK 2 expression. The biological function of microRNAs is to control target genes. In a previous study, we found that metformin significantly inhibited the expression of AMPK $\alpha 2$ and increased the expression of miR-27a. Whether AMPK $\alpha 2$ is the target gene of miR-27a remained unclear.
Therefore, we first used western blot analyses to detect the expression of the AMPK $\alpha 2$ protein in MCF-7 cells by transfecting $300 \mathrm{pmol} \mathrm{miR-27a} \mathrm{mimics} \mathrm{and} \mathrm{miR-27a} \mathrm{inhibitors.} \mathrm{The}$ results showed that the expression of $A M P K \alpha 2$ proteins in the miR-27a overexpression group was significantly decreased, and the expression of AMPK $\alpha 2$ in the miR-27a inhibitor group was significantly increased (Fig. $4 \mathrm{~A}$ and $\mathrm{B} ; \mathrm{P}<0.05$ ).

Furthermore, we used luciferase assays to confirm that the effects of AMPK $\alpha 2$ were truly mediated by direct binding of miR-27a to the 3'-UTR of the AMPK $\alpha 2$ gene. These assays were conducted in MCF-7 cells. Luciferase reporter plasmids were prepared and co-transfected with miR-27a mimics, causing overexpression of miR-27a. This overexpression of miR-27a significantly decreased AMPK $\alpha 2$ 3'-UTR luciferase activity $(\mathrm{F}=0.021, \mathrm{P}=0.001)$. However, no such suppression 
was observed when we performed similar experiments using a mutated 3'-UTR (Fig. 4C and D). All the data confirmed that the binding of miR-27a to the 3'-UTR of the AMPK $\alpha 2$ gene was required to produce these effects.

\section{Discussion}

In the present study, we described another new form of regulation for metformin on breast cancer in regards to miRNAs. We showed that miR-27a mediates the antiproliferative effects of metformin in MCF-7 cells through its target gene, AMPK 22 .

Recent pilot studies carried out using population registries raise the possibility that metformin may reduce cancer risk and/or improve cancer prognosis. One study showed an unexpectedly lower risk of cancer diagnosis among diabetic patients taking metformin compared with a control group of diabetics using other treatments (22); another study showed lower cancer-specific mortality among subjects with diabetes using metformin compared with diabetics using other treatments (23). Zhou et al indicated that metformin does not directly activate AMPK (24). Shaw et al showed that metformin activated AMPK and reduced blood glucose, which depended on LKBl (25). LKB1 was previously described as a tumor-suppressor gene with relevance to epithelial neoplasia (26). The mammalian target of rapamycin (mTOR) is an integrated signal for the regulation of cell growth factors and nutrient metabolism (27). The activation of AMPK mediated by metformin was found to inhibit mTOR signaling and the effects of metformin on tumor cells was through activation of AMPK, acting on mTOR and activating tumor suppressor gene 2 (TSC2), therefore playing an antitumor role (28). Zakikhani et al found that metformin can inhibit the growth of MCF-7 cells by activating the AMPK pathway in vitro, and when the concentration of metformin increased, the activity of AMPK increased gradually, and the inhibition of mTOR became more obvious (29). The present study also drew the conclusion that with the gradual increase in metformin concentration and the exposure time, the proportion of apoptosis in MCF-7 cells was also increased. In the present study, $20 \mathrm{mmol} / \mathrm{l}$ metformin activated the cleavage of caspase- 3 and $40 \mathrm{mmol} / 1$ metformin augmented this tendency.

Furthermore, in vivo and in vitro studies indicated that metformin inhibited the growth of tumor cells in the G0/G1 phase, and inhibited the expression of cyclin D1 in MCF-7 cells, decreasing the growth activity of the cells (30). In addition, studies by Hirsch et al confirmed that metformin effectively killed breast cancer stem cells (31). Cufí et al and other studies showed that metformin affected TGF induced by EMT and played a role in tumorigenesis (32).

The research on miRNAs has attracted great attention in recent years. miRNAs play roles in almost all aspects of cancer biology, such as proliferation, apoptosis, invasion/metastasis and angiogenesis. miRNAs post-transcriptionally repress gene expression by recognizing complementary target sites in the 3'-untranslated region (3'-UTR) of target mRNAs. Approximately 50\% of human miRNA genes were confirmed to be located in a mutated region that was associated with tumors. This suggests that the abnormal expression of miRNAs may be closely related to the formation of tumors and other diseases (33). In recent years, abnormal changes in miRNA expression have been closely associated with the occurrence of many malignant tumors, such as acute lymphoblastic leukemia (34), adenocarcinoma (9), pancreatic (35), breast (36) and liver cancer (37). Therefore, in this experiment we aimed to verify whether metformin can alter the expression of miRNAs and promote apoptosis in cancer cells.

In the present study, we confirmed that the expression of miR-27a after metformin intervention was significantly lower compared with the control group. Therefore, we can see that metformin inhibited the expression of miR-27a in MCF-7 cells; however, the specific mechanism needs to be further studied.

Data revealed a significant and widespread reduction in AMPK $\alpha 2$ expression in mammary epithelial carcinoma, regardless of tumor grade, lymph node status or patient age. Fox et al conducted a series of experiments to verify if re-expressing the AMPK $\alpha 2$ isoform could affect tumorigenic properties. The results showed that AMPK $\alpha 2$ through cyclin D1 arrested the cell cycle through the mTOR pathway to reduce protein synthesis, and also acted directly on P53, leading to apoptosis. Lee et al indicated that the loss of AMPK $\alpha 2$ activity caused the instability of P53 and led to the formation of liver cancer cells (38). The mechanism of the downregulation of AMPK $\alpha 2$ is unknown and warrants further investigation. However, data from the present study demonstrated that AMPK $\alpha 2$ was suppressed at the mRNA level, suggesting that RNA degradation control mechanisms may play a significant role. Therefore, this experiment tried to explain this phenomenon from the relationship between miRNAs and their target genes.

The results of the present study confirmed that after a certain concentration of metformin intervention, the expression of miR-27a was significantly downregulated, and the expression of AMPK $\alpha 2$ mRNA was significantly higher than that of the control group $(\mathrm{P}<0.05)$. Western blot data also confirmed that AMPKa2 protein expression was also increased. In order to understand the relationship between miR-27a and AMPK $\alpha 2$, the miR-27a RNA oligos were used to transfect MCF-7 cells. We found that the expression of AMPK $\alpha 2$ was significantly decreased after transfection with miR-27a mimics in a concentration-dependent manner, and western blot experiments confirmed this point. The MTT assay also confirmed the same results, showing that the group transfection with miR-27a mimics had mean OD values significantly higher than that of the others, and the proliferation inhibition rate was significantly decreased.

These results indicated that AMPK $\alpha 2$ may be a downstream target gene of miR-27a. However, a clear relationship between miR-27a and AMPK $\alpha 2$ was demonstrated through luciferase reporter assays targeting AMPK $\alpha 2-U T R$, which verified the results of the experiment. Overexpression of miR-27a significantly suppressed AMPK $\alpha 2$ 3'-UTR luciferase activity. However, the repression was not observed when we performed the same experiments using mutated 3'-UTR.

Finally, it can be concluded that metformin reduced the expression of miR-27a in a specific way, and miR-27a combined with the AMPK $\alpha 2$ 3'-UTR, meaning that metformin could increase the expression of AMPK $\alpha 2$. Accordingly, the expression of P53 may increase, which activated caspase-3, resulting in the apoptosis of MCF-7 cells. This may be a novel mechanism for inhibiting breast cancer cell growth by metformin. 
There are many other details which need to be elucidated through experiments. It must be determined whether metformin inhibits miR-27a expression in breast cancer cell lines other than MCF-7. Analysis of a panel of breast cancer cell lines for miR-27a and AMPK $\alpha 2$ expression levels must be carried out to determine if they are inversely correlated, Similarly, its clinical relevance should be determined, i.e. by performing a meta-analysis study using breast cancer patient data (it would be interesting to analyze miR-27a expression in metformin-treated tumors vs. untreated tumors). It also must be determined whether miR-27a targets AMPK $\alpha 2$ by inducing RNA destabilization or translational repression. This requires further investigation. As miRNAs target multiple genes simultaneously, in order to prove that miR-27a mediates the antiproliferation effects of metformin in MCF-7 through AMPK $\alpha 2$ targeting, we must perform AMPK $\alpha 2$ rescue experiments (i.e. overepxression of AMPK $\alpha 2$ in the presence of miR-27a or AMPK $\alpha 2$ knockdown in the presence of miR-27a inhibitor).

Our conclusions were rooted in the laboratory-based study, and the dose of metformin we used based on the references we had read. Actually, the dose we used was 3 orders of magnitude higher than the dose used clinically. We chose cells, namely tissue, as our subject, and long-time use of metformin could cause drug accumulation in tissues, leading to higher concentration in tissue than in serum. Furthermore, Cooper et al showed that a clinically relevant dose of metformin for 11 days could cause increased $\left[{ }^{18} \mathrm{~F}\right] \mathrm{FDG}$, suggesting longer incubations with low dose of metformin could cause similar effects as higher dose over shorter time periods (39). Thus, our design was reasonable.

The importance of this experiment lies in that it implies a new mechanism of how metformin activates AMPK, and in the future whether we can conduct a new drug concerning miR-27a antagonist, may be vital for tumor patients.

miRNA-based therapy has gradually advanced. miRNA analogs or miRNA expression vectors have been successfully used in the expression of miRNAs in vitro. miR-145 and 5-FU have been combined to treat breast cancer, and it was found that it can play a role in cancer therapy (40). Research has shown that the combination of 5-FU and miR-21 can effectively inhibit the growth of breast cancer cells. Therefore, we believe that miRNA-based treatment programs may be applied for the treatment of human cancer and achieve satisfactory efficacy.

\section{References}

1. Noto $\mathrm{H}$, Goto A, Tsujimoto $\mathrm{T}$ and Noda $\mathrm{M}$ : Cancer risk in diabetic patients treated with metformin: A systematic review and meta-analysis. PLoS One 7: e33411, 2012.

2. Witters LA: The blooming of the French lilac. J Clin Invest 108: 1105-1107, 2001.

3. Bodmer M, Meier C, Krähenbühl S, Jick SS and Meier CR: Long-term metformin use is associated with decreased risk of breast cancer. Diabetes Care 33: 1304-1308, 2010.

4. Chuang JC and Jones PA: Epigenetics and microRNAs. Pediatr Res 61: 24R-29R, 2007.

5. Latronico MV, Catalucci D and Condorelli G: MicroRNA and cardiac pathologies. Physiol Genomics 34: 239-242, 2008.

6. Liu J, Valencia-Sanchez MA, Hannon GJ and Parker R: MicroRNA-dependent localization of targeted mRNAs to mammalian P-bodies. Nat Cell Biol 7: 719-723, 2005.
7. Filipowicz W, Bhattacharyya SN and Sonenberg N: Mechanisms of post-transcriptional regulation by microRNAs: Are the answers in sight? Nat Rev Genet 9: 102-114, 2008.

8. Esquela-Kerscher A and Slack FJ: Oncomirs - microRNAs with a role in cancer. Nat Rev Cancer 6: 259-269, 2006.

9. Liu T, Tang H, Lang Y, Liu M and Li X: MicroRNA-27a functions as an oncogene in gastric adenocarcinoma by targeting prohibitin. Cancer Lett 273: 233-242, 2009.

10. Mertens-Talcott SU, Chintharlapalli S, Li X and Safe S: The oncogenic microRNA-27a targets genes that regulate specificity protein transcription factors and the $\mathrm{G}_{2}-\mathrm{M}$ checkpoint in MDA-MB-231 breast cancer cells. Cancer Res 67: 11001-11011, 2007.

11. Wang X, Tang S, Le SY, Lu R, Rader JS, Meyers C and Zheng ZM: Aberrant expression of oncogenic and tumor-suppressive microRNAs in cervical cancer is required for cancer cell growth. PLoS One 3: e2557, 2008.

12. Lerner $M$, Lundgren $J$, Akhoondi S, Jahn A, Ng HF, Akbari Moqadam F, Oude Vrielink JA, Agami R, Den Boer ML, Grandér D, et al: MiRNA-27a controls FBW7/hCDC4-dependent cyclin E degradation and cell cycle progression. Cell Cycle 10: 2172-2183, 2011.

13. Mertens-Talcott SU, Noratto GD, Li X, Angel-Morales G, Bertoldi MC and Safe S: Betulinic acid decreases ER-negative breast cancer cell growth in vitro and in vivo: role of Sp transcription factors and microRNA-27a:ZBTB10. Mol Carcinog 52: 591-602, 2013.

14. Banerjee N, Talcott S, Safe S and Mertens-Talcott SU: Cytotoxicity of pomegranate polyphenolics in breast cancer cells in vitro and vivo: Potential role of miRNA-27a and miRNA-155 in cell survival and inflammation. Breast Cancer Res Treat 136: 21-34, 2012.

15. Hardie DG: AMP-activated protein kinase: An energy sensor that regulates all aspects of cell function. Genes Dev 25: 1895-1908, 2011.

16. Hardie DG, Carling D and Gamblin SJ: AMP-activated protein kinase: Also regulated by ADP? Trends Biochem Sci 36: 470-477, 2011.

17. Jørgensen SB, Viollet B, Andreelli F, Frøsig C, Birk JB, Schjerling $P$, Vaulont $S$, Richter EA and Wojtaszewski JF: Knockout of the $\alpha_{2}$ but not $\alpha_{1}$ 5'-AMP-activated protein kinase isoform abolishes 5-aminoimidazole-4-carboxamide-1- $\beta$-4ribofuranosidebut not contraction-induced glucose uptake in skeletal muscle. J Biol Chem 279: 1070-1079, 2004.

18. Musi N, Hirshman MF, Nygren J, Svanfeldt M, Bavenholm P, Rooyackers O, Zhou G, Williamson JM, Ljunqvist O, Efendic S, et al: Metformin increases AMP-activated protein kinase activity in skeletal muscle of subjects with type 2 diabetes. Diabetes 51 : 2074-2081, 2002.

19. Fox MM, Phoenix KN, Kopsiaftis SG and Claffey KP: AMP-activated protein kinase $\alpha 2$ isoform suppression in primary breast cancer alters AMPK growth control and apoptotic signaling. Genes Cancer 4: 3-14, 2013.

20. Kim YH, Liang H, Liu X, Lee JS, Cho JY, Cheong JH, Kim H, Li M, Downey TJ, Dyer MD, et al: AMPKa modulation in cancer progression: Multilayer integrative analysis of the whole transcriptome in Asian gastric cancer. Cancer Res 72: 2512-2521, 2012.

21. Liu J, Liu W, Ying H, Zhao W and Zhang H: Analysis of microRNA expression profile induced by AICAR in mouse hepatocytes. Gene 512: 364-372, 2013.

22. Evans JM, Donnelly LA, Emslie-Smith AM, Alessi DR and Morris AD: Metformin and reduced risk of cancer in diabetic patients. BMJ 330: 1304-1305, 2005.

23. Bowker SL, Majumdar SR, Veugelers P and Johnson JA: Increased cancer-related mortality for patients with type 2 diabetes who use sulfonylureas or insulin: Response to Farooki and Schneider. Diabetes Care 29: 1990-1991, 2006.

24. Zhou G, Myers R, Li Y, Chen Y, Shen X, Fenyk-Melody J, Wu M, Ventre J, Doebber T, Fujii N, et al: Role of AMP-activated protein kinase in mechanism of metformin action. J Clin Invest 108: 1167-1174, 2001.

25. Shaw RJ, Lamia KA, Vasquez D, Koo SH, Bardeesy N, Depinho RA, Montminy M and Cantley LC: The kinase LKB1 mediates glucose homeostasis in liver and therapeutic effects of metformin. Science 310: 1642-1646, 2005.

26. Hemminki A, Avizienyte E, Roth S, Loukola A, Aaltonen LA, Järvinen $\mathrm{H}$ and de la Chapelle A: A serine/threonine kinase gene defective in Peutz-Jeghers syndrome. Duodecim 114: 667-668, 1998 (In Finnish). 
27. Markman B, Atzori F, Pérez-García J, Tabernero J and Baselga J: Status of PI3K inhibition and biomarker development in cancer therapeutics. Ann Oncol 21: 683-691, 2010.

28. Bell DS: Successful utilization of aliskiren, a direct renin inhibitor in Bartter syndrome. South Med J 102: 413-415, 2009.

29. Zakikhani M, Dowling R, Fantus IG, Sonenberg N and Pollak M: Metformin is an AMP kinase-dependent growth inhibitor for breast cancer cells. Cancer Res 66: 10269-10273, 2006.

30. Ben Sahra I, Laurent K, Loubat A, Giorgetti-Peraldi S, Colosetti P, Auberger P, Tanti JF, Le Marchand-Brustel Y and Bost F: The antidiabetic drug metformin exerts an antitumoral effect in vitro and in vivo through a decrease of cyclin D1 level. Oncogene 27: 3576-3586, 2008.

31. Hirsch HA, Iliopoulos D, Tsichlis PN and Struhl K: Metformin selectively targets cancer stem cells, and acts together with chemotherapy to block tumor growth and prolong remission. Cancer Res 69: 7507-7511, 2009.

32. CufíS, Vazquez-Martin A,Oliveras-Ferraros C,Martin-CastilloB, Joven $\mathbf{J}$ and Menendez JA: Metformin against TGF $\beta$-induced epithelial-to-mesenchymal transition (EMT): From cancer stem cells to aging-associated fibrosis. Cell Cycle 9: 4461-4468, 2010.

33. Lee YS and Dutta A: MicroRNAs in cancer. Annu Rev Pathol 4: 199-227, 2009

34. Kim KB, Lotan R, Yue P, Sporn MB, Suh N, Gribble GW, Honda T, Wu GS, Hong WK and Sun SY: Identification of a nove synthetic triterpenoid, methyl-2-cyano-3,12-dioxooleana-1,9dien-28-oate, that potently induces caspase-mediated apoptosis in human lung cancer cells. Mol Cancer Ther 1: 177-184, 2002.
35. Ma Y, Yu S, Zhao W, Lu Z and Chen J: miR-27a regulates the growth, colony formation and migration of pancreatic cancer cells by targeting Sprouty2. Cancer Lett 298: 150-158, 2010.

36. Hassan MQ, Gordon JA, Beloti MM, Croce CM, van Wijnen AJ, Stein JL, Stein GS and Lian JB: A network connecting Runx2, SATB2, and the miR-23a 27a 24-2 cluster regulates the osteoblast differentiation program. Proc Natl Acad Sci USA 107: 19879-19884, 2010.

37. Dobreva G, Chahrour M, Dautzenberg M, Chirivella L, Kanzler B, Fariñas I, Karsenty G and Grosschedl R: SATB2 is a multifunctional determinant of craniofacial patterning and osteoblast differentiation. Cell 125: 971-986, 2006.

38. Lee CW, Wong LL, Tse EY, Liu HF, Leong VY, Lee JM, Hardie DG, Ng IO and Ching YP: AMPK promotes p53 acetylation via phosphorylation and inactivation of SIRT1 in liver cancer cells. Cancer Res 72: 4394-4404, 2012.

39. Cooper AC, Fleming IN, Phyu SM and Smith TA: Changes in [18F]Fluoro-2-deoxy-D-glucose incorporation induced by doxorubicin and anti-HER antibodies by breast cancer cells modulated by co-treatment with metformin and its effects on intracellular signalling. J Cancer Res Clin Oncol 141: 1523-1532, 2015.

40. Kim SJ, Oh JS, Shin JY, Lee KD, Sung KW, Nam SJ and Chun KH: Development of microRNA-145 for therapeutic application in breast cancer. J Control Release 155: 427-434, 2011 